\title{
The importance of information and communication technologies (ICTs) in Zimbabwe: A case study of social media in the tourism and hospitality sector.
}

\author{
Anos Machinjike1 and Farai Choga2 \\ ${ }^{1,2}$ Zimbabwe Open University \\ Graduate School of Business \\ 115 Kwame Nkrumah Avenue \\ Michael Court,Harare, Zimbabwe
}

\section{Abstract}

The Postal and Telecommunications Authority of Zimbabwe (POTRAZ) statistics point to the rise in the use of social media in Zimbabwe. The United Nations World Tourism Organisation(UNWTO) also allude to the important role played by the tourism industry in the economic development and growth around the world. This study sought to find a nexus between the exponential rise in usage of social media and its impact on the tourism and hospitality in Zimbabwe which ultimately could contribute to the economic growth of the country. The research set out to focus on establishing from tourists, the influence of social media in the choice of tourist destinations as well as to determine the role of social media as a marketing tool from players in the tourism and hospitality sector. Other objectives were to identify popular social media platforms as well as the benefits and challenges arising out of the use of social media in the industry. The qualitative research methodology was used for the study where face to face and telephonic interviews as well as in-depth emailed questionnaires were used to as data collection instruments using a purposive sampling method. The findings of the study show that social media plays a significant role in influencing people's decisions on choice of tourist destinations and is also an important, cost effective, efficient and convenient marketing tool. Popularity of social media is also driven by its affordability and interactive nature. Findings also point out some challenges arising out of use of social media. The study concluded that social media plays a significant role in the tourism and hospitality sector. The study therefore recommended the adoption of social media for the purposes of creating positive perceptions on destinations to improve the pull power of destinations. The study also recommended the need to uplift the profile of social media in organisations through employment of appropriate staff to advance digital marketing on social media platforms. Another recommendation was to call for the enactment of policies to penalise detractors and culprits who peddle falsehoods and fake news on social media for ulterior motives.

Key Words: information and communication technologies (ICTs), social media,tourism and hospitality sector

\section{Background of the Study}

The web based technologies have enhanced the concept of globalisation due to use of faster, more accessible services and efficient communication networks powered by social networking sites such as WhatsApp, Viber, Twitter, Facebook, You Tube, LinkedIn and 
many others that provide micro blogging, video blogging, chatting, video calling, text, video and image sharing services (Sharma, 2016). The divergent issues raised by Sharma (2016) and Hunt et al (2018) spurred these researchers to establish the importance of ICTs in Zimbabwe's economic development based on a case study of social media in the tourism sector.

Statistics by the Tourism Barometer show that arrivals in Africa increased by 4\%. According to the Zimbabwe Tourism Authority's 2017 Tourism Trends and Statistics, Zimbabwe received a total of 2,422,930 tourist arrivals in 2017, $12 \%$ up from 2,167,686 received in 2016. There is, however, a gap on related information on the importance of social media influence in the tourism and hospitality industry of Zimbabwe.

\section{Statement of the Problem}

Social media play an important role in shaping tourist perception on travel destinations. Unfortunately, there is lack of adequate information on the role played by social media in influencing tourist visits to Zimbabwe.

\section{Research Objectives}

This research was guided by the following objectives:

- To determine the importance of social media as a marketing tool for tourism attraction to Zimbabwe.

- To identify benefits to tourism, arising from usage of social media.

- To identify the challenges faced by the tourism sector due to usage of social media.

\section{Literature Review}

This research has theoretical underpinnings within the theories of mass communication which carries the information sharing role. There is particular interest in the priming theory in mass communication which was put forward by Iyengar, Peters and Kinder in 1982. The priming theory states that the media has an effect on decision making. Priming provides basic perception and relative comparison, which makes judgment easier and quicker. The priming theory which is viewed as a predecessor to the agenda setting theory, also states that media images influences people's decisions through control of the people in a psychological way.

\section{Social media as a marketing tool}

The growth of the use of the Internet in tourism marketing witnessed the use of the social media as a key communication tool with customers (Mhizha, Nyaruwata, Munyanyiwa and Mandebvu, 2015).The explosion of internet users on social media had a huge impact on the tourism and hospitality industry (Yazdanifard and Yee, 2014). The stock of social media for destination marketing organisations rose significantly. Yazdanifard and Yee (2014) asserted that in the tourism and hospitality industry, social networking sites were one of the essential tools that played an important and beneficial role. They further posited that content on social media affected the marketing of tourist destinations in both positive and negative way. Kait(2018) confirmed this by stating that the role of social media to the tourism products/services proved to be a good strategic technique not only in the improvement of the quality of business but also provision of large scale cost control measures in the industry.

Yazdanifard and Yee (2014) posited that business success determined by marketing decisions based on consumer needs, changed society and development of technology. The two added that, the explosion of social usage significantly impacted on the marketing of hospitality and tourism services. Kait(2018) asserted that social media provided suitable tools for generating dialogue between the organisation and its stakeholders. The assertion was supported by Yazdanifard and Yee (2014) who stated that social media provided social communication 
services which created brand awareness and build a good image for the brand. Underutilisation of social media by destination marketers, according to Popesku (2014) derailed the competitive advantage of destinations. ICTs and social media availed a large selection of tourist destinations to potential guests. Volo (2010) found that returning visitors were largest audience of destination marketing blogs. Roskos-Ewoldsen and Carpentier (2002) pointed out the ubiquitous nature of the media, that made it a powerful tool for priming how people think and behave.

Social marketing provided brand visibility and awareness that was essential in converting potential customers to loyal customers (Lim, 2010). The same author stated that the creation of thematic content generated brand awareness and the brand would be top of mind with the consumers if they decided to buy the product or services. Kait(2018) noted that hotels needed to improve the use of social media tools for attracting the interest of their stakeholders. The online community of Brazilian hotels realised that these online platforms were a great opportunity for reaching out and becoming more involved in matters that involved their brand as well as services on offer (ibid). However, (ibid), in the case of Russia and India, it seemed the conditions necessary to generate such online participation were not sufficiently established. In view of the above, it would be interesting to determine the value put in social media marketing by tourism promotion agencies in Zimbabwe such as the ZTA and the Ministry of Tourism and Hospitality Industry and tour operators hence the motivation to undertake this research.

Tourism marketing involves finding out what tourists want (marketing research) and developing suitable offerings (product development), telling them what is available (promotions) and providing instructions as to where they can buy the offerings (place) so that they in turn receive value (pricing) and the tourism organizations make money (George, 2001).Yazdanifard and Yee (2014) alluded to the fact that consumer behaviour was significantly affected by social networking sites which provided platforms for consumers to connect with organisations and other consumers. Kait(2018) advocated for the improved use of social media to increase stakeholder participation, highlighting that, proper use of such tools by hotels not only serve to respond to their customer expectations but also provides a useful feedback channel regarding products and services. Increased activity on social media and meaningful use of these tools help hotel companies to discover new strategies for overall performance improvement.

\section{Social media benefits}

Mizha et al, (2015) asserted that social media had become a major source of information for consumers when planning holidays. They further stated that comments and reviews on the quality of services provided by different enterprises influence the decisions of the potential tourists as to which destinations to travel to and which operators to use when purchasing holiday activities. The fact that travel information can now be easily accessed through mobile phones and computers has special implications for organisations operating the tourism industry (Matikiti, Mpinganjira and Roberts-Lombard, 2017). Lyu and Wang (2015) and Matikiti et al (2017) revealed that the introduction of social media and other internet technologies led to a significant drop in the number of people who use traditional information centres, travel agents and tour operators to obtain travel information in Korea. They noted that people preferred social media to traditional sources of information. Siricharoen (2012) noted that through blogs, social search, social networking and book marking, social media presents the marketer with a rich set of new tools in the effort to generate new business. Social media introduced substantial and pervasive changes to communication between 
organisations, communities and individuals (Siricharoen, 2012).Siricharoen (2012) further revealed that the Cone Business in Social Media study conducted in 2008 showed that 93\% of Americans believed that a company must have social media presence. Eighty five percent (85\%) of Americans in the Cone Business study believed that social media must be used to interact with consumers and solving problems, soliciting feedback on products and services and to develop new ways for consumer interaction with the brand as well as for marketing. Abuhashesh (2014) pointed out that the tools required by companies to effectively advertise on the social media platform were very cost effective and require little investment in relevant technologies. Abuhashesh (2014) further noted that social media exposed small players to a large audience through global reach through a low cost strategy. Abuhashesh (2014) alluded to the risks that arise out of the customers' communication power where they can expose quality and operational issues to the rest of the consumer market to the detriment of the company. The use of social medial was a key tool that has fundamentally changed the way travellers and tourists search, find, read and trust as well as collaboratively produce information about tourism suppliers and tourism destinations (Sigala, Christon and Gretzel, 2016). Minazzi (2015) complemented the statement by stating that travellers had become more demanding and looked for differentiated and personalised services, therefore tourism companies do benefit from collecting customer information at each stage of tourism experience, which was only possible because of user generated content published online. Such information helped companies with better understanding of the customer needs, preparation for personalised services and more generally develop customer centric strategies (Minazzi, 2015).

Mhizha et al (2015) quoted a number of authors who stated that within Africa, very limited research had undertaken to assess the level of adoption of the internet and social media as tools for marketing tourism products and services. This research would go a long way in trying to close this information gap as it tries to establish the importance that is placed on social media in destination marketing in Zimbabwe.

Social media was a point of reference for travellers who often based their expectations on other travellers' experiences (Igboayaka, 2015). Other travellers experience at a particular destination provided beneficial information useful in risk avoidance and also to boost up travellers' confidence while deciding on travel plans (Fotis, Buhalis and Rossides, 2012). Social media can be accessed via mobile smartphones hence in view of the high rate of usage of mobile communications; it makes social media readily available.

Social media allows connection with the consumers. Social media in fact improved communication with consumers. Improved communications with consumers brought numerous benefits for the industry such as building relationships, creating brand awareness and maintaining customer loyalty (Popesku, 2014). Communicating with the consumers helped to make a positive impression of the company and also to build trust and strengthen the relationship with new and loyal customers. Just having a conversation with consumers by using advertising words was not going to help, instead, the conversation has to be trustable so that consumers will be persuaded with those words and so become interested in the product and services of a brand(Seth, 2012).

Social media was also a good platform for promotion of tourism products because of the large numbers of social media users with Facebook boasting of over 2.2 billion users (Dreamworks, 2018). Last minute promotions can be posted on social media without having to print leaflets for distribution (Yazdanifard and Yee, 2014). Social media also assisted in targeting clients or groups of people who are within a given social area of influence as people congregate on a WhatsApp 
group or as members of the same Facebook page. Hotels and other tourism industry players got to know customer behaviours and preferences from close interaction and use such information to improve their service standards (Murray and Waller, 2007). The priming theory is silent on issues specific to social media but notes that media effected actions of people and can influence people to act in a certain way and to make certain value judgements.

\section{Social Media Challenges}

Social networking mostly depends on the general perception of word-of-mouth (WOM) or now called the electronic word of mouth (eWOM) which contents are generated by consumers online (Brooner and de Hoog, 2011). Information provided to consumers through WOM and eWOMcan either promote or defame a brand. An argument by Lange-Faria and Elliot(2012) postulated that eWOM, comments were posted from unknown online users whose reputation and identity lacked, so it was difficult for consumers to trust the information posted. Rishi and Bandyopadhyay (2018) posited that half of all crimes in Britain, particularly rape and death threats were committed online using Facebook. Brooner and de Hoog, (2011) went further to state that social media influenced the tourism industry in both positive and negative way. Organisations have no monopoly on information dissemination and on framing of the message.Consumers can change the narrative. A consumer might give a false statement that is negative by sharing a testimonial or recounting an experience or downloading content based on his or her personal impression towards the company, and others in the network may be affected by the opinion of the consumer (Seth, 2012).

Rishi and Bandyopadhyay (2018) alluded to the issue of social engineering hacking, as a vector attack that relies heavily on human interaction and often trick people into breaking normal security procedures. They added that social media make it easier because people post most of the items that make up their passwords like favourite colours, pest names, children's names and birthday dates. Information that is publicly available through social media and online activity make users vulnerable (Rishi and Bandyopadhyay, 2018). They cited the example of a television celebrity, Kim Kardhashian, who was robbed at gunpoint in Paris after having flashed her US\$4 million ring on social media.

User interactions with false content rose steadily on both Facebook and Twitter through the end of 2016 (Hunt, Gentzkow and Yu, 2018).Fake news refer to inaccurate news items, posts, comments, photo-shopped images or edited videos meant to intentionally mislead readers, gain attention, deceive and/or damage reputation (TechTarget, 2018). Misinformation is created with an intention to manipulate the consumers of the information to response and act in a certain way (Hunt et al, 2018). The disinformation carried by fake news can spread quickly when it is aligned with the point of view held by the audience because such content is likely not to be questioned.Tourist perceptions could be negatively shaped by such because of social media. The Internet has enabled the spread of fake news by providing a host of lowcost distribution channels(Hunt et al, 2018). The posting of fake news on discussion forums, blogs and social media sites requires very little technical know-how, reaching enormous audiences over the course of a few hours (TechTarget 2018).

Engagement with tourists as part of this research would confirm or deny that such challenges, where social media is inaccessible, in the tourism sector. Rishi and Bandyopadhyay (2018) proposed that social media users needed to pay attention to privacy matters they readily made freely and publicly available. The two also proposed that social network providers must consider the importance of user privacy, safety and security of social media applications and the smartphones because of the dire implications such as the Kardashian robbery. Rishi and Bandyopadhyay (2018) also proposed the need for enactment of social media policy where 
government would institute restrictive regulations for marketers, smartphone manufacturers and social media networks.

\section{Research Methodology}

A qualitative approach, open-ended questionnaires and interviews were employed to gather data. Tourists, government and private business participants were used in this study with response rate of $88 \%$.

\section{Data Analysis and Discussion}

Theparticipants responses accede to the assertion that social media influenced on choice of tourist destination. The responses showed that social media was an important conduit for information sharing, which is supported by Yazdanifard and Yee (2014) who postured that consumers used social media as trusted sources of information because it was posted by people they relate to online or had a passing acquaintance.Popesku (2014) concurred that through user generated content, the growth and prevalence of social media allowed users to corroborate, communicate and publish own blogs, vlogs and reviews. These reviews tended to either influence tourists for or against visiting a particular destination depending on the narration presented.

Responses also showed that social media was also used for showing off and bragging by individuals through exposing personal developments, activities and achievements. One participant stated that "charmed by images and video clips as well as reviews of online friends enjoying themselves while on holiday in Victoria Falls and this inspired her to come and personally enjoy the experience”. Popesku (2014) and Brooner and de Hoog (2011) concurred that social media was fast becoming a primary medium for sharing travel information. Lange-Faria and Elliot (2012) supported the findings of this study by stating that travellers placed a high degree of trust in their social media networks for gathering and synthesising information by other travellers to form a decision about choice of visiting a particular destination. The same assertion was in agreement with the theory of priming which implies that media, and in this case social media had significant influence in decision making. Hence the finding confirms, what the study set out to establish, that social media had an influence on choice of tourist destination.

Tourists in this study acknowledged that social media was a critical tool for sending out warnings on possible dangers that have a threatening effect on the safety of life.Another participant in the study noted the importance of safety and security considerations stating that "terrorism, violence and political instability, cost of services and affordability, weather and climatic conditions, health issues - diseases outbreaks cause people to avoid the affected places, accessibility of the place - the mode of transport involved and communication links".

These views were cited by a number of participants in the study who pointed out that social media allowed them access to critical information for them to make informed judgements on these key considerations before undertaking trips to particular destinations. This was supported by Popesku (2014) who acknowledged that personal recommendations were particularly important in choice of tourist destinations.

Another aspect through with social media influences choice of tourist destination as provided for by the responses to this study include conveniently availing information about prices for products and services on offer, affording a cheap line of communication for booking and any other enquiries pertaining to a particular destination.

The study responses also showed that social media offerred a platform to grow personal brand and followership. This finding was informed by the request for participant's insights on how else social media impacted on the tourism and hospitality industry. Participants also 
suggested the use of brand influencers and online celebrities could play a significant marketing role for particular top notch destinations.

From the perspective of players in the tourism and hospitality sector, influence of social media on choice of tourist destination was hinged on it being a provider of platform for product and service promotion. Some of the responses alluded to the use of social media for destination marketing, destination and brand promotion, receiving feedback from clients, receiving and responding to enquiries, receiving recommendations, clarifying misinformation and engaging and interacting with clients. This implies that social media platforms were helping businesses to engage with their clientele and encouraging them to choose their destination or brand by offering promotions to entice potential tourists to visit. Hence the study responses showed that social medial platforms were used to create awareness of promotions on offer, reduction in prices for accommodation and tours as well as other services that tour and safari providers offer. Mhizha et al (2015) share similar views with the findings of the study by stating that social media provided a key communication tool that influences various facets of business in the tourism and hospitality industry.

Social media platforms according to the responses were also known to provide brand visibility and awareness. Once that rapport has been created then, the choice of a restaurant or accommodation provider is a foregone conclusion. Lim (2010) attested to the importance of brand visibility and awareness in the tourism and hospitality sector, while Kait (2018) noted that hotels needed to improve the use of social media tools for attracting the interest of patrons.

The cross section of participants representing Government, parastatals and private entities, who participated in this study attested to the fact that social media played a role key in the tourism and hospitality industry. This buttressed the literature that is available to the effect that social media influenced destination marketing efforts. Popesku (2014), Kait (2018), Yazdanifard and Yee (2014) all attested to the versatility of the role of social media in the tourism and hospitality industry where it was used for both business and leisure purposes.

The findings from this study supported the assumptions advanced by the priming theory and confirmed the role of the media in influencing personal decisions and value judgements even in choice of destinations in the tourism and hospitality industry. In this case, social media is the conduit for the information that is key in the decision making of tourists whether to visit or not to visit particular destinations. This was supported by a participant who stated that "social media is a user friendly, convenient and cost effective source of useful information for planning trips because social media trends rally around topical issues which can be warnings, advisory or educational, which most users re-tweet, forward and share with fellow online colleagues". These views buttressed the notion advanced by the priming theory which states that the media plays a key informational role when making decisions.

Players in the tourism and hospitality industry pointed out that social media helped them to access a wide range of audience despite the geographical distances. This was in agreement to the posture by Yazdanifard and Lee (2014), that the stock of social media for destination marketing was raised significantly in the recent years. Social media was also useful for brand promotion, visibility and awareness as well as advertisement of promotions to lure clients to visit and enjoy products and services on offer. This was buttressed by Yazdanifard and Yee (2014), Kait (2018 and Volo (2010) who said that social media provided tools for generating dialogue between organisations and its stakeholders and build social communication platforms which created brand awareness and build a good image. Popesku (2014) further added that underutilisation of social media by destination marketers derailed the competitive advantage of destinations.

Roskos - Ewoldsen and Carpentier (2002) supported the theory of priming in that the ubiquitous nature of the media made it a powerful tool for priming how people think and 
behave. Thus as the findings on the use of social media showed, user generated content couldbe structured and packaged to market tourist attractions and destinations for the benefit of the tourism and hospitality sector. As Lim (2010) put it, creation of thematic content generated brand awareness to such an extent that the brand would be top of the consumers' mind when they decided on buying a product or service. It thus tallies with the findings of this study that the respondents alluded to the presence of a website, at least one social media account and an ICT policy within their organisations.

Through social media marketing, findings of the study showed that, service providers directed engagement to target audience. Marketers also used the audio - visual power of the medium to package content in innovative and interesting ways for the purposes of luring potential tourists. Affordability and convenience of the platform in terms of the cost of marketing was pointed out by a number of respondents. Accommodation providers at Victoria Falls, in Zimbabwe were excited by the innovation in marketing arising out of social media which led to the increased business opportunities. This can be viewed in parallel to the views in Kait (2018) who cited the online community in Brazilian hotels as having realised great opportunities through reaching out and becoming more involved in issues concerning their brands. The subtle arising from the findings of the study showed that all levels within organisations engaged in the study were well aware of the power of social media in marketing and brand promotion.

ZTA and the Ministry of Environment, Tourism and Hospitality Industry specifically confirmed their role in the destination promotion as well as the convenience that they were afforded by the advent of social media which made their promotional efforts easy, effective and less costly. Abuhashesh (2014) attested to the cost effectiveness of using social media in marketing. The ZTA has a Facebook page and a twitter handle together.Other players in the industry had Facebook pages and twitter handles which they used for propagating promotional posts, comments, reviews, images and videos that aided the marketing efforts of the organisations in the industry.

From the perspective of a marketer, the research findings were in agreement with Siricharoen (2012) who stated that through blogs, comments and reviews, social media presented the marketer with rich and innovative set of new tools for generating new business. The research study findings confirmed that social media was an important tool for marketing in the tourism and hospitality industry which reducing the cost of marketing allowing businesses to generate higher profits.

The responses to this study showed that there were a number of benefits that accrue to users of social media in both categories of individual tourists and that of business organisations in the tourism and hospitality sector. Affordability was cited as one of the greatest benefit arising from the use of social media platforms. Social media platforms were generally much cheaper than traditional communication platforms therefore it encouraged engagement and interaction for business and leisure at very low cost. Seth (2012), Popesku (2014) and Yazdanfard and Yee (2014) attested to the affordability and convenience brought about by social media as espoused by the findings in this study.

Accessibility of social media platforms was another benefit to both individual tourists and business entities. For tourists, social media was a rich source of information which primed tourists to informed decision making. This buttressed the assumption made by the priming theory on the importance of information in decision making. Tourists access trending information and their decision making was influenced by the effect and repetition of exposure as given by the priming theory of mass communication. Seth (2012) supported the findings by stating that social platforms were easily accessible and straight forward.

Participant responses showed that another important benefit for tourists was that it provided social proof from those who have been there through shared experiences either through 
reviews, comments, audio, videos and blogs. Fotis, Buhalis and Rossides (2012) support this finding, saying that travellerexperienced at a particular destination provided beneficial information useful in risk avoidance and boost travellers' confidence when making travel plans.

In the category of business entities in the tourism and hospitality industry, the most popular benefit identified by study participants was the fact that social media platforms allowed them access to global market reach.Study participants also stated that social media opened the business to worldwide business opportunities as businesses interact with potential clients from across the globe potentially turning a previously localised business into a global venture. This finding was supported by Siricharoen (2012), Brooner and de Hoog (2011) as well as Lange-Faria and Elliot (2012).

Responses also showed that social media significantly reduced business expenditure through reduced marketing costs resulting in businesses realising increased profits. Assenov and Khurana (2012) realised this by stating that tourism and hospitality players invested in online presence because it was inexpensive but effective as a marketing tool.

Another benefit of social media espoused by the participants was that it offered direct engagement with customers and clients. Participants added that social media engagement between business and its clients occured without intermediaries therefore allowing business to access primary data from clients and creating a personal bond with clients which often resulted in brand loyalty. Popesku (2014) and Seth (2012) concurred with these findings. The same for brand awareness and recognition which also led to business development and growth.

Seth (2012), Popesku (2014) and others, in support of the findings of the study that pointed out the importance of social media as a business and interactive communication tool which availed feedback important in the improvement of product and service quality. Total quality management was associated with addressing customer needs hence client feedback was an important ingredient in the attainment of improved quality which led to business growth.

Though social media was an exciting innovation, the respondents noted some challenges that were associated with its use. The challenges to social media use that afflicted individual tourists were to a large extent similar to those that affect players in the tourism and hospitality industry. The silver lining was that these did not override the benefits.

Participants cited the misrepresentation of information and the scourge of fake news that happenedin social media as a challenge. Responses alluded to the manipulation of information that could be deliberately done by detractors of a brand in an effort to divest the interest in that particular brand or destination. One participant in the study highlighted that "social media was exaggerating the economic and social challenges in Zimbabwe as these were not reflected on the ground in view of the numbers of fellow tourists that he had seen during his visit to the country".

One participant noted that social media created information overflow and which created a hard time for individuals in making decisions to settle on a particular destination. The same participant proposed that this could be managed through assignment of officers dedicated to management of social media platforms within organisations so that they could package the information for effective delivery of the message to the targeted market.

On use of recommendations from anonymous social media accounts or those who used pseudonyms, one of the respondents said;

"people distort, misinform and deceive while hiding behind the cover of anonymity therefore it may be risky to adopt recommendations from ghost accounts lest you may be led into dubious destinations and circumstances". 
These views were echoed by a number of users who felt that it might not be reasonable for one to rely on information from a source whose credibility and integrity could not be verified because they operated under a ghost account.

Rishi and Bandyopadhyay (2018) and Brooner and de Hoog (2011) while agreeable that the presence of challenges in the use of social media also attested to it having both positive and negative influences to the tourism industry. Respondents suggested that the problem of fake news and negative exaggerations of situations could be curtailed by introduction of penalties for culprits found to be propagating negative and unsubstantiated information.

This enactment of penalties was a new finding from the study that could be further developed in a concept to safe guard the social media platforms not only in the tourism and hospitality sector but across the whole spectrum of the economy and even at international level.The challenges to social media use in the tourism and hospitality industry were also informed by the priming theory of mass communication and can actually influencing decisions against visiting particular destinations.

\section{Recommendations}

Players in the tourism and hospitality industry should enhance the use of social media for marketing and destination promotion purposes.There was also need to package and disseminate attractive destination promotion messages which could convince tourists to choose destinations and brands in Zimbabwe.Business entities have to adopt the innovative marketing strategies including digital marketing riding on affordable social media platforms. The Government of Zimbabwe should facilitate dissemination ICT infrastructure to ensure that tourists aided the brand marketing efforts through posting reviews and sharing tour experiences. There was also need to employ dedicated officials responsible for social media platforms for the organisational authority to address misrepresentations that emanate from uninformed quarters and detractors. The destination promotion agencies should also undertake a research study to establish the value of brand influencers and online celebrities for the purpose of improving the marketing power of social media.

\section{References}

1. DreamWorks (2018) Top 15 Most popular networking sites adapted from https://www.dreamgrow.com/top-15-most-popular-social-networking-sites/

2. Brooner, F. \& de Hoog, R. (2011) Vacationers and eWOM: Who posts and why, where and what? Journal of Travel Research.Vol.50. No.1, pp. 15-26.

3. Fotis. J., Buhalis. D.\&Rossides. N. (2012).SocialMedia Use and Impact during the Holiday Travel Planning Process. Retrieved from:http://eprints.bournemouth.ac.uk/19262/1/Fotis_et_al_2012_Social_media_use_and _impact_during_the_holiday_travel_planning_process.pdf

4. Hunt, A., Gentzkow, M., \& Yu, C. (2018) Trends in the Diffusion of Misinformation on Social Media. New York University, Stanford University - October 2018

5. Hunt,D. Robertson, D. \&Pow, A. (2018). The Counselor's Role in the Age of Social Media and Fake News, Journal of Creativity in Mental Health, 13:4, 405417, DOI: $10.1080 / 15401383.2018 .1462748$

6. Igboayaka, J.C.E. (2015)Using Social Media Networks for Measuring Consumer Confidence: Problems, Issues and Prospects. University of Ottawa. Canada.

7. Kait, R (2018) Impact and Role of Social Media in Tourism Sector, Opportunities and Challenges for Tourism and Hospitality in BRIC Nations, Dhiman M.C. (Ed) , IGI Global, Hershey PA. 
8. Lange- Faria, W. \& Elliot, S. (2012) Understanding the role of social media in destination marketing, Tourismo: An international multidisciplinary journal of tourism Volume 7, Number 1, Spring-Summer 2012, pp, 193-211.

9. Lim, W. (2010) The effects of social media networks in the hospitality industry. UNLV Theses, Dissertations, Professional Papers and Capstones, 693. On https://digitalscholarship.unlv.edu/thesesdissertations/693

10. Mhizha, A., Nyaruwata, S., Munynyiwa, T. and Mandebvu, G. (2015) The adoption of social media platforms in tourism and hospitality marketing: The case of Small and Medium scale enterprises (SMEs) in Harare. International Journal of Development and Sustainability.Vol.4.No.6 (2015). pp. 635-649.

11. Minazzi, R. (2015). Social Media Marketing in Tourism and Hospitality.Springer International. London.

12. Murray, K. and Waller, R. (2007) Social networking goes abroad. International Educator, $16(3)$, pp 56-59.

13. Popesku, J. (2014). Social media as a tool of destination marketing organisations, EBusiness in tourism and hospitality industry, Impact of Internet on Business Activities in Serbia and Worldwide (DOI: 10.15308/SINTEZA-2014-715-721 Sinteza 2014)

14. Rishi, B. And Bandyopadhyay, S. (2018). (Ed). Contemporary Issues in Social Media Marketing.

15. Roskos-Ewoldsen, D. Roskos-Ewoldsen, B and DillmanCarpentier, F.R. (2002) Media Priming: A Synthesis in Media Effects: Advances in Theory and Research

16. Seth, G. (2012). Analyzing the Effects of Social Media on the Hospitality Industry.

17. Sigala, M., Christon, E., and Gretzel, U. (2016) Social Media in Travel, Tourism and Hospitality - Theory Practice and Cases. Routledge. London.

18. TechTarget (2018).https://whatis.techtarget.com/definition/fake-news accessed on 22/01/2019

19. Volo, S. (2010), Bloggers' reported tourist experiences: Their utility as tourism data source and their effect on prospective tourists,Journal of Vacation Marketing, Vol. 16, No. 4, pp. $297-311$.

20. World Tourism Organization (2005) UNWTO Tourism Highlights-2005 Edition. Madrid, Spain

21. Yazdanifard, R,.and Yee, L.T. (2014) Impact of social networking sites on Hospitality and Tourism Industries, Global Journal of Human-Social Science: E Economies Vol (14) Issue 8 Ver 1 